\title{
Data Summary of Municipal Solid Waste Management Alternatives
}

\section{Executive Summary}

SRI International

Menlo Park, California

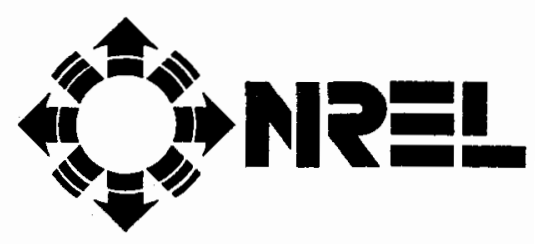

National Renewable Energy Laboratory 1617 Cole Boulevard

Golden, Colorado 80401-3393

Operated by Midwest Research Institute for the U.S. Department of Energy

Under Contract No. DE-AC02-83CH10093 


\section{Data Summary of Municipal Solid Waste Management Alternatives}

\section{Executive Summar}

NREL Technical Monitors: Bimleshwar Gupta

SRI International

Menlo Park, California

\section{Philip Shepherd}

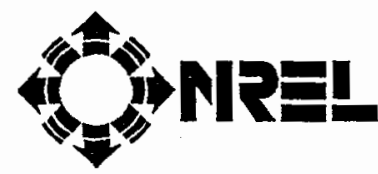

National Renewable Energy Laboratory (formerly the Solar Energy Research Institute) 1617 Cole Boulevard Golden, Colorado 80401-3393

A Division of Midwest Research Institute Operated for the U.S. Department of Energy under Contract No. DE-AC02-83CH10093

Prepared under subcontract no: RF-1-1103

August 1992 
On September 16, 1991 the Solar Energy Institute was designated a national laboratory, and its name was changed to the National Renewable Energy Laboratory.

\title{
NOTICE
}

This report was prepared as an account of work sponsored by an agency of the United States government. Neither the United States government nor any agency thereof, nor any of their employees, makes any warranty, express or implied, or assumes any legal liability or responsibility for the accuracy, completeness, or usefulness of any information, apparatus, product, or process disclosed, or represents that its use would not infringe privately owned rights. Reference herein to any specific commercial product, process, or service by trade name, trademark, manufacturer, or otherwise does not necessarily constitute or imply its endorsement, recommendation, or favoring by the United States government or any agency thereof. The views and opinions of authors expressed herein do not necessarily state or reflect those of the United States government or any agency thereof.

\author{
Printed in the United States of America \\ Available from: \\ National Technical Information Service \\ U.S. Department of Commerce \\ 5285 Port Royal Road \\ Springfield, VA22161 \\ Price: Microfiche A01 \\ Printed Copy A03
}

Codes are used for pricing all publications. The code is determined by the number of pages in the publication. Information pertaining to the pricing codes can be found in the current issue of the following publications which are generally available in most libraries: Energy Research Abstracts (ERA); Government Reports Announcements and Index (GRA and I); Scientific and Technical Abstract Reports (STAR); and publication NTIS-PR-360 available from NTIS at the above address. 


\section{PROJECT OBJECTIVES}

The overall objective of the study summarized in this report was to gather data on waste management technologies to allow comparison of various alternatives for managing municipal solid waste (MSW). The specific objectives of the study were to:

1. Compile detailed data for existing waste management technologies on costs, environmental releases, energy requirements and production, and coproducts such as recycled materials and compost.

2. Identify missing information necessary to make energy, economic, and environmental comparisons of various MSW management technologies, and define needed research that could enhance the usefulness of the technology.

3. Develop a data base that can be used to identify the technology that best meets specific criteria defined by a user of the data base. 


\section{PREFACE}

This report provides data for use in evaluating the proven technologies and combinations of technologies that might be considered for managing municipal solid waste (MSW). It covers five major methods for MSW management in common use today:

- Landfilling

- Mass combustion for energy recovery

- Production of refuse-derived fuel (RDF)

- Collection/separation of recyclables

- Composting.

It also provides information on four MSW management technologies that are not widely used at present:

- Anaerobic digestion

- Cofiring of MSW with coal

- Gasification

- Pyrolysis.

To the extent possible with available reliable data, the report presents information for each proven MSW technology on:

- Net energy balances

- Environmental releases ',

- Economics.

In addition to data about individual operations, the report presents net energy balances and inventories of environmental releases from selected combined MSW management strategies that use two or more separate operations.

The scope of the report extends from the waste's origin (defined as the point at which the waste is set out for collection), through transportation and processing operations, to its final disposition (e.g., recycling and remanufacturing, combustion, or landfilling operations). Data for all operations are presented on a consistent basis: one (1) ton of municipal (i.e., residential, commercial, and institutional) waste at the collection point. The data provided in tables in this report are also available in a spreadsheet that allows the user to modify the information and to tailor the combination strategies to fit a particular need. In the process of developing the data presented here, one goal was to identify where gaps in the available information exist as a guide to future data collection and research efforts.

Selection of an MSW management plan may be influenced by many factors, in addition to the technical performance and economics of each option. The importance of or emphasis on each of these factors is likely to differ for each jurisdiction. The factors below fall into this category, but were excluded from the scope of this report:

- Ecological impacts

- Health risks

- Social and other values

- Specific jurisdictional circumstances.

The MSW technologies covered in this report do not exhaust the plausible components of waste management strategies. For example, many communities have initiated efforts to decrease the amount of waste that must be handled by promoting source reduction and waste minimization, including backyard composting, but data on those programs are not analyzed here. 


\section{CONTENTS}

PROJECT OBJECTIVES

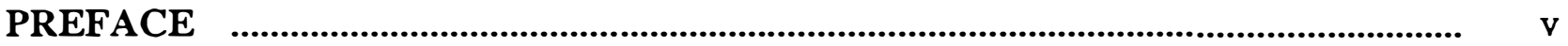

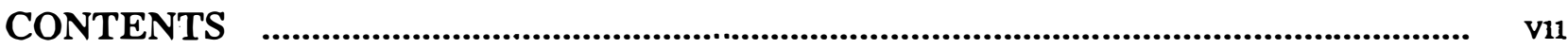

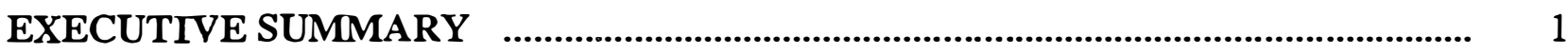

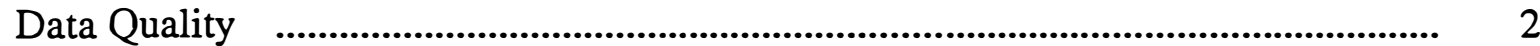

Major Technologies …….......................................................................... 2

Less Commonly Used Technologies $\quad$.................................................................... 3

Collection and Transportation $\quad$......................................................................... 3

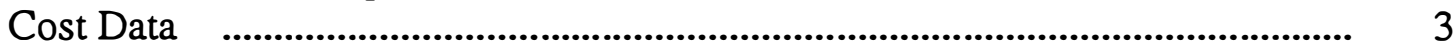

Methodology .................................................................................................... 4

Basis for the Comparisons: a Life-Cycle Analysis …........................................ 4

Energy and Emissions ................................................................................ 4

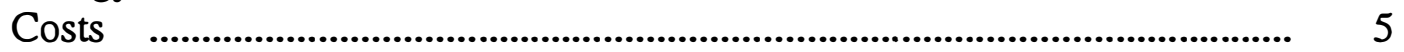

Data Formats ……................................................................................ 5

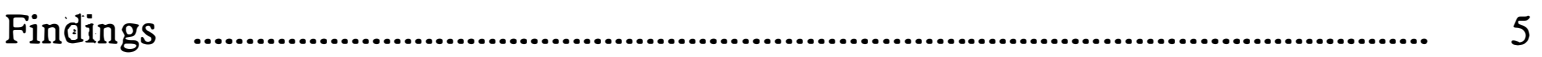

Overview of MSW Management in the United States ……............................. 5

r.Collection and Transportation $\quad$........................................................................ 6

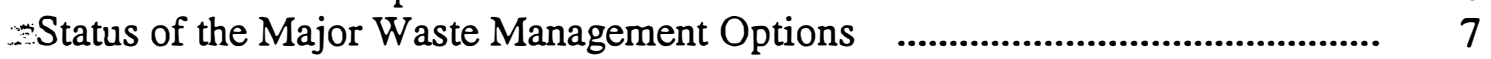

iz. Sanitary Landfilling ………………………….............................................. 7

Combustion with Energy Recovery ............................................................... 8

Curbside Separation and Mixed Waste Separation and

Recycling ................................................................................................. 9

Composting …….......................................................................................... 10

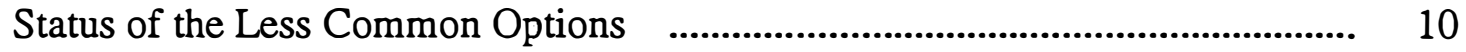

Cofiring RDF with Coal ............................................................................. 10

Anaerobic Digestion ....................................................................................... 11

Gasification/Pyrolysis ............................................................................ 11

Life-Cycle Energy and Environmental Releases from Common Integrated Strategies ................................................................................. 11

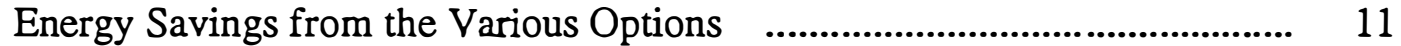

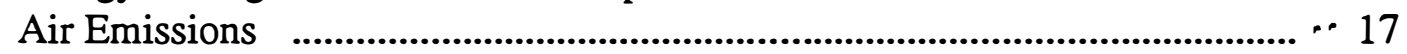

Water Emissions ................................................................................ 17

Landfill Space .......................................................................................... 19

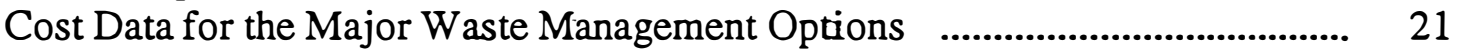

Missing Data and Research Needs …..................................................................... 21

Other Project Documentation .................................................................................. 26 


\section{EXECUTIVE SUMMARY}

Selecting an approach for managing a community's municipal solid waste (MSW) is a difficult, technically complex process. The problem is compounded by a lack of comprehensive sources of current data on the various possible approaches to MSW management. In general, the best available data are for systems that include environmental controls. Thus, extensive data have been published on air emissions from the combustion of waste, and significant amounts of data are available on air emissions and leachate from landfills. Few data exist on composting or on curbside collection, separation, and remanufacturing of recyclable materials. In addition, very few life-cycle assessments of waste management alternatives have been published. The National Renewable Energy Laboratory (NREL) began a review for the Department of Energy (DOE) to determine what is already. known and establish a consistent basis for comparing the environmental releases, energy use and production, and economics of waste management options.

This study was initiated to compile publicly available data on the five major options commonly used for MSW management today:

- Landfilling

- Mass burning for energy recovery

- Production and combustion of refuse-derived fuel (RDF)

- Collection/separation of recyclable materials

- Composting.

The report on the study, "Data Summary of Municipal Solid Waste Management Alternatives," and this executive summary summarize the data on those options. The report also provides some data on energy, environmental releases, and economics for the following less commonly used options:

- Anaerobic digestion

- Cofiring of RDF with coal

- Gasification/pyrolysis.

Because no commercial anaerobic digestion and gasification/pyrolysis facilities have operated in the United States, the data for these options are based on pilot plant results.

Many communities will use more than one option to manage MSW. Such combinations of options are identified here as "integrated strategies." For example, some communities"öffer curbside collection of recyclable materials in addition to collection of the remaining MSW for landfilling or combustion. Some communities collect yard waste for composting, as well. This report provides the data needed to compare the wide variety of integrated strategies. Realistically, it was expected that some information would be unavailable, and that some 
published data would require validation. One goal of the study was to identify missing information and to define additional research needed to improve the options for managing MSW.

This report was intended to help communities make informed decisions by giving them consistent data describing their possible choices. The scope of the study excluded a number of factors that a community may wish to consider, such as ecological impacts, health risks, local social values, and the regulatory requirements of specific jurisdictions. Because the report focuses on options for managing waste that is set out for collection, it does not discuss programs designed to reduce the amount of waste to be picked up for disposal, such as source reduction and backyard composting.

\section{DATA QUALITY}

In this effort to provide data on a consistent basis for the variety of technologies covered in the study, it was necessary to use data of widely varying quality. Furthermore, in converting all the data to a consistent basis, as described below under "Methodology," it was necessary to make a number of assumptions. The assumptions used in the conversions reduce the accuracy of the estimates presented here, independently from the quality of the original data on which the estimates were based.

The availability of extensive, reliable data varied significantly from process to process, as outlined below. For combustion processes, extensive data are available on costs, and wellverified data are available on energy and emissions. Less consistent data are available on landfilling, and few data have been found on collection, separation, and remanufacturing and on composting.

Data on collection and transportation and cost data for all technologies involve special problems. They are therefore discussed separately in a later subsection of this summary.

\section{Major Technologies}

In general, the data for rapidly completed processes (such as combustion) are much more extensive than data for processes that occur slowly (such as the degradation in landfills). The original data used for energy and emissions from mass burning and combustion of RDF are quite reliable because the performance of those systems can be accurately measured. Data on the slower processes like landfilling are suspect because little reliable information is available on energy use and production and environmental releases generated over long periods.

Among the slower processes, the best data appear to be those on landfill gas generation; however, individual sources report widely varying rates of production from different landfills. The least accurate estimates used in the study are on the amounts and composition of water releases from landfills containing MSW or ash. Some of the data on the composition of the leachate reflect measurements made by researchers following strict quality assurance procedures, and those data seem reliable. However, all the sources report samples taken on a single occasion or over relatively brief periods of time. No studies quantifying water releases over long periods were found, and the method used in this study to extrapolate emissions over 20 years from individual measurements is speculative. 
Composting is a relatively slow process. Data on composting are incomplete, and researchers have neither accurately measured composting emissions, as they have for combustion emissions, nor developed sophisticated models, as they have for landfills.

Recycling of MSW through curbside collection of recyclables or separation of mixed waste is a relatively new and changing approach. Recycling also involves many more processing steps than landfilling or combustion. Collection is a major contributor to the energy and emissions profiles for recycling, and the limitations on the collection and transportation data used in this study outlined below strongly affect the quality of the recycling data as well. There is currently no complete or consistent accounting of the amounts of MSW collected for recycling and the amounts actually recycled. The energy and emissions from the recycling (remanufacturing) processes themselves are not well characterized, and they will vary depending on the products made from the recycled material. Published estimates of the energy required for recycling and manufacture from virgin resources appear to be high-quality data, but they reflect processes in use in the mid-1970s. Available data comparing emissions from remanufacturing with those from manufacturing virgin materials are so inadequate that they are not included in the report, although the differences may be significant.

\section{Less Commonly Used Technologies}

Two of the less commonly used options-anaerobic digestion and gasification/ pyrolysisare not used commercially in the United States. The data on those options presented in the report are therefore based on pilot plants. They do not provide an adequate basis for comparisons with other processes.

The third less commonly used option-cofiring of RDF with coal—is a commercial process, although it is used at only a few facilities. Reliable data on energy production are available for cofiring, but few studies of emissions have been made.

\section{Collection and Transportation}

The estimates of amounts of material collected and of energy and emissions for collection and transportation used in this study are based on the experience of a single community. In addition, the data provided by the community were not independently verified. Thus, the collection and transportation data in this report are intended to provide a basis for making order-ofmagnitude estimates of the effects of altering the collection procedures used in a community, and for comparing the sources and magnitudes of emissions from collection with those from process steps. The estimates cannot be expected to be representative of other communities. No data were found on energy required for transportation of collected ferrous metals, aluminum, glass, or paper to the point of remanufacture.

\section{Cost Data}

The cost estimates are adequate only for making order-of-magnitude comparisons and identifying trends. Although all the data found in the literature were updated to a single year using an appropriate inflation index, many other factors, such as the impact of different technologies, make direct comparisons impossible. Differing accounting systems also make comparative costs difficult to determine. Better estimates of relative capital and operating costs could be developed by designing reference plants for each technology and estimating the costs of those plants on a consistent basis. 


\section{METHODOLOGY}

\section{Basis for the Comparisons: a Life-Cycle Analysis}

The best available data have been converted to a consistent basis for comparisons. In compiling data about net energy requirements and environmental releases, a life-cycle assessment approach was used that generally followed a typical life-cycle assessment practice. ${ }^{*}$ As applied to a given MSW management option, a life-cycle assessment is a comprehensive, quantitative description of the energy and materials used and the wastes released in all steps of the option.

The data for each option and strategy are reported on the basis of one ton of MSW, set out for collection. In the strategies that used curbside collection of recyclables in combination with a disposal technology such as landfilling or combustion, the energy and emissions for both curbside collection and the disposal technology are based on one ton of material left at the curb; that is, for example, if about $14 \%$ of total MSW is separately collected for recycling, energy and emissions are reported for the sum of 280 pounds left for curbside collection of recyclables and 1,720 pounds left for disposal.

\section{Energy and Emissions}

In calculating energy data, a ton of waste is followed through all transportation ${ }^{\dagger}$ and processing operations to its final disposition (e.g., recycling and remanufacturing, combustion with energy recovery, or landfilling operations with gas recovery). Emissions data are presented for all steps except remanufacturing, as discussed above.

The time frame covered by the comparisons is 20 years. That unusually long period was chosen to permit comparisons of energy recovery from landfill gas collection with that for combustion of MSW in a waste-to-energy facility. Gas forms very slowly in a landfill, and choosing a shorter time frame for the analysis would underestimate the amount of energy that might be recovered from the waste. A period longer than 20 years was not considered because gas production in landfill-gas-to-energy operations may fall to an uneconomic level within that time, and current commercial practice is to close the energy recovery operations when they have operated for 20 years or less.

For consistency, the same 20-year period was used in considering all other emissions from the landfill, including the gás not recovered and the leachate (liquid that leaks from the landfill). The leachate from the ash from combustion processes was therefore also followed for 20 years, although releases to the air during combustion are accounted for when the MSW is burned. Landfill emissions will continue for a period longer than the 20 years considered in this analysis.

Other factors complicate the life-cycle analysis of materials separation, collection, and recycling. Recycling of suitable components of $\mathrm{MSW}$ involves five steps:

- Separating reusable materials from other municipal waste, often at curbside, but sometimes at a central facility

* As described, for example, by the Society of Environmental Toxicology and Chemistry (SETAC).

$i$ Energy consumed in transportation is reported as the fuel consumed. About $15 \%$ of the Btu content of crude oil is used in converting it to gasoline or diesel fuel and transporing it to the point of use. That factor is not included in the estimates. 
- Transporting and processing (including remanufacturing) the separated materials for use as replacements for virgin materials

- Managing the wastes from separation and recycling

- Returning the materials to commerce, often as parts of other products

- Selling the recycled product to consumers.

The life-cycle analysis methodology requires that all these steps be included; the total estimates of emissions and energy balances can then be compared with those for the original manufacturing process, including the acquisition of raw materials. This report provides energy balances for recycling, but data on environmental releases during manufacturing and remanufacturing are not available.

\section{Costs}

Data on capital and operating costs for the individual options were converted to 1991 dollars per ton of daily capacity to provide a consistent basis for cost comparisons. The PEPCOST Index, which was designed to make such conversions for SRI International's Process Economics Program, was used.

\section{Data Formats}

A data base was constructed that includes the energy and emissions data for each waste management option and for each step in a comprehensive MSW management strategy: collection, processing, disposal of residues, and, if appropriate, recycling. Because a community ultimately chooses and implements a strategy that includes at least the first three of these steps and may choose a strategy that incorporates several individual options, the data base combines the energy and emissions for each component in proportion to its contribution to the overall strategy for treatment of the waste.

The data base is available in electronic form for analyzing various possible MSW management strategies. Users can change variables in the data base (e.g., transportation distances, volume of recyclables collected, truck fleet fuel consumption) to reflect a particular community's circumstances.

\section{FINDINGS}

\section{Overview of MSW Management in the United States}

The United States generated 180 million tons of municipal solid waste in $1988 .^{*} \mathrm{MSW}$ is estimated to be growing at rates of $0.75 \%$ to $1.5 \%$ per year-i.e., at the same rate as population growth to twice the rate of population growth.

Today, $69-73 \%$ of MSW is landfilled, and landfill gas is recovered for energy at about 128 of the nation's larger landfills; $17 \%$ of it is burned, $94 \%$ of that amount (or almost $16 \%$ of total MSW) for energy recovery. Estimates of the percentage of MSW that is recycled vary

* This estimate includes residential, commercial, and institutional solid waste, plus some similar types of wastes from industrial sources, in accordance with the U.S. Environmental Protection Agency/s (EPA's) "Characterization of MSW in the U.S.: 1990 Update." 
significantly; the U.S. Environmental Protection Agency (EPA) and the Office of Technology Assessment (OTA) have published estimates of 10-14\%. Composting accounts for a small percentage of waste treatment.

The EPA has set a national voluntary goal of reducing the quantity of MSW by $25 \%$ through source reduction and recycling by 1992 , and at least 21 states have adopted laws to mandate or encourage separation of recyclable materials from MSW. The quantity of waste recycled by programs under community control is not well documented.

\section{Collection and Transportation}

MSW management includes curbside collection of the waste, transportation of the waste to a landfill or a processing facility (e.g., a combustor or a materials recovery facility), and possibly transportation of the residue from processing to a landfill. Although many models of collection and transportation requirements for various types of collection programs have been developed, it proved difficult to find actual data on energy and emissions for these steps. Accordingly, this study used data on transportation energy requirements supplied by one community. The city had operated a curbside collection program for recyclables for many years, and it initiated a program for curbside collection of yard waste about a year before this study began. It is not necessarily typical of other communities.

The community supplied data on actual tonnages collected by each truck in each of the three separate collection programs; the number of trucks operated and the number of miles traveled by each truck; and the fuel consumption on each route. Fuel use per ton of material picked up on each route was lowest for collecting household and commercial MSW. About 2.5 times more fuel was used to pick up a ton of separated recyclables, and about 600 times more fuel was used to collect a ton of yard waste (because of the small quantities collected on each route in that program).

To develop the estimates presented in this summary, these fuel use rates were converted to energy use per ton of MSW at the curb, and then apportioned according to the amounts set out. The energy and emissions results are extremely sensitive to the amount collected by each truck. Therefore, energy use per ton of material collected increases as additional curbside collection programs are implemented.

No direct emission measurements for MSW collection or curbside collection vehicles have been made during actual operation. Emissions from collection and transportation were therefore estimated on the basis of the actual fuel use by assuming that the emissions per unit of fuel met the maximum permissible emission limits for heavy-duty diesel truck engines operating according to a specified EPA procedure that simulates freeway and city driving. When these engine limits have been compared to actual emissions from vehicles under the same load and speed conditions, the results vary by $20-50 \%$ for emissions of different types; for example, the operating vehicles emit larger quantities of hydrocarbons and particulates, but smaller amounts of nitrogen oxides and carbon monoxide than the tested engines. The duty cycle of the MSW packer trucks in these tests is quite different, in terms of stop-start frequency and compactor operation, from the typical duty cycle for the trucks modeled by the EPA. Therefore, in developing emissions estimates for this study, the emissions limits were increased by a factor of four to provide a better approximation of actual emissions. 


\section{Status of the Major Waste Management Options}

\section{Sanitary Landfilling}

Open landfills have been used as a waste management method for centuries. Rules and regulations for construction and operation of solid waste landfills were established by the Resource Conservation and Recovery Act (RCRA) of 1976 as a way to reduce the number of open dumps common at the time. Since then, landfill requirements have become more stringent. Careful enclosure of MSW, by providing liners underneath it, covering the landfill with dirt ("daily cover") at the end of each day, installing gas collection systems, and capping the landfill when it is filled, permits the collection of between $30 \%$ and $85 \%$ of the methane, carbon dioxide, and other organic gases generated by the waste. Those gases can be burned for energy recovery if the quantity generated is large enough to justify the expense of the equipment. More than 100 landfills recover landfill gas for energy. The majority produce electricity, but in a few locations, the gas is used for process heat, or it is upgraded to pipeline quality and sold.

Although only about 160 of the nation's approximately 6,000 operating landfills are operating or plan to operate landfill gas-to-energy plants, the energy and emissions data in this report are based on landfill with gas recovery. The largest landfills (about 200 have a capacity of more than 1,000 tons per day) are more likely to include the energy recovery facilities, and those landfills now receive more than $40 \%$ of all MSW landfilled in the United States. In comparison with facilities that either collect landfill gas and flare it or allow the gas to escape into the atmosphere, landfill gas-to-energy operations reduce environmental releases of methane while providing an energy benefit.

Most landfills reach capacity because they fill up or reach practical height limits, rather than by reaching a weight limit. Therefore, efforts to reduce the amount of space that MSW occupies can extend the life of a landfill. Combustion and recycling programs can help to reduce waste volume. Other options include:

1. Shredding or compressing MSW in bales-These processes can significantly increase the density of the MSW. Both approaches are practiced at a few locations in the United States.

2. Stimulating the decomposition of waste-In research programs at a number of U.S. sites, leachate is being recirculated and appropriate nutrients are being added to speed the rate of decomposition. More rapid decomposition generates larger quantities of recoverable gas (up to double normal production) within a shorter time period, reduces the amount of leachate that must be collected and treated, and permits the closed landfill to be returned to unrestricted use sooner or "mined" for reuse, as discussed below. Research on this approach is being conducted at a number of U.S. sites.

3. "Mining" old landfills-Old landfills, particularly those that have been infiltrated by large amounts of rain or need to be remediated to prevent groundwater contamination, can be dug up and processed to separate the dirt and compost fraction for use as compost or landfill cover. The resulting reduction in landfill volume permits reuse of the site, which is already zoned for landfilling. 


\section{Combustion with Energy Recovery}

Like landfilling, open buming has been used for centuries to dispose of waste. In the United States, combustion of MSW to recover energy in the form of saleable electricity was first practiced in about 1902, in New York City.

Many newer plants now recover energy. In modern plants, energy can be recovered in the form of hot water, steam, and electricity, or in some combination of those three forms. Until the 1970s, MSW combustors included little, if any, air pollution control equipment. The units of the 1950 s and 1960s were generally marked by bad odors and smoke. They were primarily operated only to reduce the volume of the waste. Since the early 1970s, increasingly stringent environmental controls have been applied; as a result, today's combustors produce less air pollution.

Two options commonly used for combustion are:

1. Mass burning

2. Preparation and combustion of refuse-derived fuel (RDF).

They differ in extent of pretreatment of the MSW before firing, the type of furnace used, and the firing conditions.

In a mass burn facility, pretreatment of the MSW includes inspection and simple separation to remove oversized and noncombustible items and unacceptable components such as obviously hazardous or explosive materials. The MSW is then fed into a combustor, where it is typically supported on a grate or hearth. Air is fed below and above the grate to promote combustion. Mass burn plants can be large facilities, with capacities of 3,000 tons of MSW per day or more; however, they can be scaled down to handle the waste from smaller communities, and modular plants with capacities as low as 25 tons per day have been built.

RDF production begins with inspection of the MSW, removal of bulky or hazardous waste, and shredding of the remaining MSW. Noncombustible materials are often separated as well. The shredded RDF is most frequently burned above a traveling grate. RDF preparation and direct firing cannot be performed economically in small plants, and the minimum size of an RDF plant tends to be large. If RDF is compressed into pellets or cubes, it can be used in existing, conventional furnaces with grates. A few operating facilities now produce such pellets or cubes at one location for sale or use at another.

The energy produced by both mass burning and RDF combustion is generally used for electrical power generation. MSW combustion can thus eliminate the nèed to mine, burn, and dispose of the residue of some of the coal or oil that would otherwise be used to generate electricity.

Regulatory requirements for control of MSW combustion have grown increasingly stringent since they were first implemented in the 1970s. For both types of options, federal regulations governing all facilities with capacities greater than 250 tons per day set limits on a range of pollutants, including acid gases, metals, and dioxins/furans. The EPA is developing comparable requirements for units with capacities of less than 250 tons per day. State and local requirements may be more stringent and may apply to even smaller combustors. Current regulations for the larger plants are more stringent than those governing fossil fuel plants.

The ash from MSW combustion and the residue from the scrubber (used to neutralize acid gases in the gas stream) are disposed of, often in landfills called "ash monofills" that contain 
only ash. Modern plants using good combustion practices can reduce the volume of MSW by up to $90 \%$. The leachate from ash monofills is normally smaller in volume than that from ordinary landfills, and the constituents of the leachate are also different.

\section{Curbside Separation and Mixed Waste Separation and Recycling}

Curbside separation and mixed waste separation and recycling permit a reduction in the amount of waste that must be handled by other MSW options. As outlined previously under "Methodology," the five steps in recycling are: (1) separating reusable materials from other waste; (2) transporting and processing (including remanufacturing) the separated materials for use as replacements for virgin materials; (3) managing the wastes from separation and recycling; (4) returning the materials to commerce; (5) selling the recycled products. At present, most recycling efforts focus on the following reusable materials: newsprint, cardboard, glass, aluminum, some tin cans, and some plastics (particularly plastic beverage containers).

Some of the statistics that indicate that recycling now manages $10 \%$ or more of the nation's MSW are reporting estimates that include the amounts of material diverted from the local landfill by separate collection of recyclables, bottle deposit laws, and separate collection of yard waste for composting. Data on the amounts of MSW that are finally remanufactured and returned to commerce have not been found; however, they are clearly lower than the total quantities collected because some of the material is used as fuel, some is lost during remanufacturing, and when market conditions are poor, some may be landfilled.

Communities that wish to include recycling in their MSW management strategies have several options for separating recyclables from other waste. They can offer convenient sites where residents can receive payment for containers (e.g., buy-back centers); provide dropoff centers that may accept a wide range of recyclable and compostable materials; implement curbside collection of recyclable materials separated by residents from other MSW; and/or process mixed waste to separate recyclables.

Either mixed MSW collected in a standard packer truck or recyclables collected separately at curbside can be sent to a materials recovery facility (MRF) for further separation and consolidation of the collected materials. MRFs can be divided into "low-tech" and "high-tech" facilities, depending on the amount of manual labor required. All MRFs rely heavily on manual labor to sort and separate grades of paper and glass bottles by color, and plastic bottles by resin type and color. Nearly all MRFs also use magnets for recovering ferrous metals, and many use balers for paper, crushers for glass, and flatteners for the aluminum cans. High-tech MRFs would generally also use additional shredders, screens, possibly air classifiers for separating heavy materials from lighter ones, and special eddy-current separators that can separate aluminum. Currently operating MRFs have sufficient design capacity to process 1 million tons per year of recyclables. Another 3 million tons of capacity are scheduled to begin operation by 1993. If all the planned facilities actually become operational, they will have the annual capacity to process $2 \%$ of all U.S. MSW in 1993.

Many communities conduct curviside collection programs for recyclables but do not operate MRFs. No data on collection rates for those programs were found.

Returning materials to beneficial use and finding markets for recycled products may present difficulties. Recent rapid growth in collection and separation programs has combined with a 
generally sluggish economy to drive down the prices paid for recyclable materials. Markets for waste paper have traditionally been highly volatile.

\section{Composting}

Composting is biological conversion of organic matter. As part of an MSW management strategy, communities can choose from two types of composting programs

1. Composting of leaves and yard waste that are collected separately from MSW

2. Composting of the mixed organics and paper in MSW, sometimes with added sewage sludge.

The technologies used for composting differ mainly in how air is supplied for the process. The presence of sufficient air is critical to control unpleasant odors during composting.

Yard waste composting is typically a relatively simple, open-air process. An optional first step is to "chip" the yard waste to reduce its size and promote the breakdown of organic matter. It is then set out in long piles that are periodically turned over to expose all the material to air. Alternatively, the piles can be placed on a porous pad that is connected to a blower to supply air.

MSW composting begins with separating the organic materials from the rest of the waste and shredding or grinding the organics (the remaining MSW, about $50 \%$ of the total, is usually landfilled). In some cases, the organics are then intially composted inside a vessel that provides mechanical agitation and forced aeration; in other cases, composting takes place entirely in the open. Enclosed composting can help to control odors through better control of aeration and temperature. In all cases, composting in a vessel is followed by additional open air composting.

Although composting has so far made a small contribution to managing MSW on a national scale, it could theoretically be used to process at least the $18-20 \%$ of MSW that is yard waste. About 1,400 composting programs are operating in the United States, but at least 500 of them are seasonal programs for leaves only. Only 16 operating plants compost an organic fraction of MSW, and 4 of those add sewage sludge. The number of operational composting facilities changes frequently. Compost made from MSW is more likely to be contaminated than compost made from separately collected yard waste, and commercial markets for MSW-derived compost are difficult to find. The compost made in some MSW composting plants ends up in landfills.

\section{Status of the Less Common Options}

\section{Cofiring RDF with Coal}

A cofiring facility at Ames, Iowa, has been operating longer than any dedicated RDF boiler. $\mathrm{RDF}$ cofiring is the most technologically proven of the less common MSW management options covered in the report. RDF can be effectively mixed with coal and burned in existing coal-fired utility boilers to produce electricity. Cofiring is an effective way to burn the RDF, which has a lower sulfur content than coal. A municipality that finds a utility willing to cofire can avoid the expense of acquiring a new combustor, boiler, air pollution control equipment, and steam turbine and generator. Several utilities now cofire RDF with coal. The disadvantages are that the coal boilers must be derated, and RDF handling is difficult. 


\section{Anaerobic Digestion}

Anaerobic digestion is a biological process similar to the decomposition that takes place in a landfill. It is applicable to the organic matter in MSW. Its advantage over landfilling is more efficient methane formation; anaerobic digestion of the organic material from 1 ton of MSW can produce 2 to 4 times as much methane in less than 3 weeks as the same ton of MSW in a landfill produces over 2-7 or more years. After minimal further treatment, the residue from the anaerobic processing can be used like compost for soil conditioning, or as fuel. New plants with recently developed technology and improved operating characteristics have been apparently successful in Europe, but no commercial anaerobic digestion plants are currently operating in the United States.

\section{Gasification/Pyrolysis}

Gasification/pyrolysis can be used to produce a fuel gas or synthesis gas consisting principally of carbon monoxide and hydrogen (once called "town gas") from MSW. The fuel is compatible with existing boilers or furnaces. The process operates at a high temperature and in the absence of air. Under special conditions, a liquid fuel or chemical feedstock could also be formed. The process has been used commercially with coal and wood chips. It was used with MSW in the United States in the 1970s, but all those plants have been shut down because of operating and financial problems. Some gasification/pyrolysis plants were built and operated in Europe in the early 1980s.

\section{Life-Cycle Energy and Environmental Releases from Common Integrated Strategies}

Because communities commonly combine more than one MSW management option into an integrated strategy for handling their waste, life-cycle analyses were conducted for common integrated strategies. Key steps in those strategies are shown in Figure ES.1. The rest of this subsection summarizes the findings of those life-cycle analyses. Note that the analyses do not include a differential credit for emissions from displaced or avoided energy. Examples include the coal displaced by buming MSW for fuel and the substitution of fossil fuel used in paper remanufacturing for the renewable fuel used for virgin paper manufacture.

\section{Energy Savings from the Various Options}

For every MSW management strategy, energy is needed for collection (e.g., to pick up and deliver the MSW) and processing (in a landfill, an MRF, or a combustion plant). The life-cycle analysis in this study compared both the energy needed for each major strategy and the energy that is produced by the strategy, if any.

When an integrated MSW management strategy generates fuel energy in excess of the amount the entire strategy requires, the energy is reported as a net Btu savings. Usually the excess energy (which is referred to as "exported energy") is generated and sold as electricity, and it therefore displaces the need to generate the same amount of electricity from a virgin fuel, most commonly coal, which provides 55\%, of U.S. electrical power, or from some other source (e.g., hydropower or nuclear). 
Figure ES.1

STRATEGIES BASED ON THE FIVE MAJOR OPTIONS

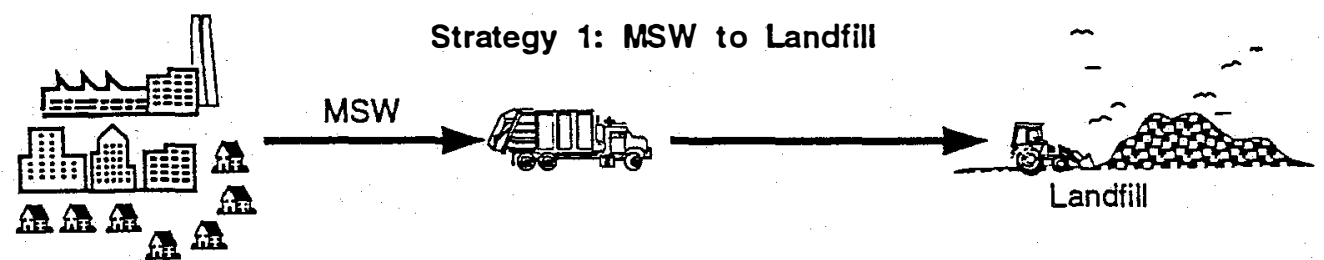

Community

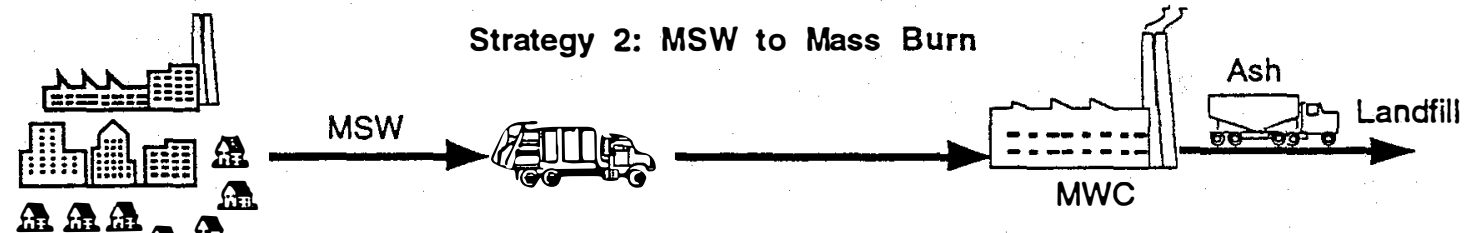

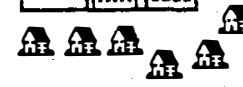

Community
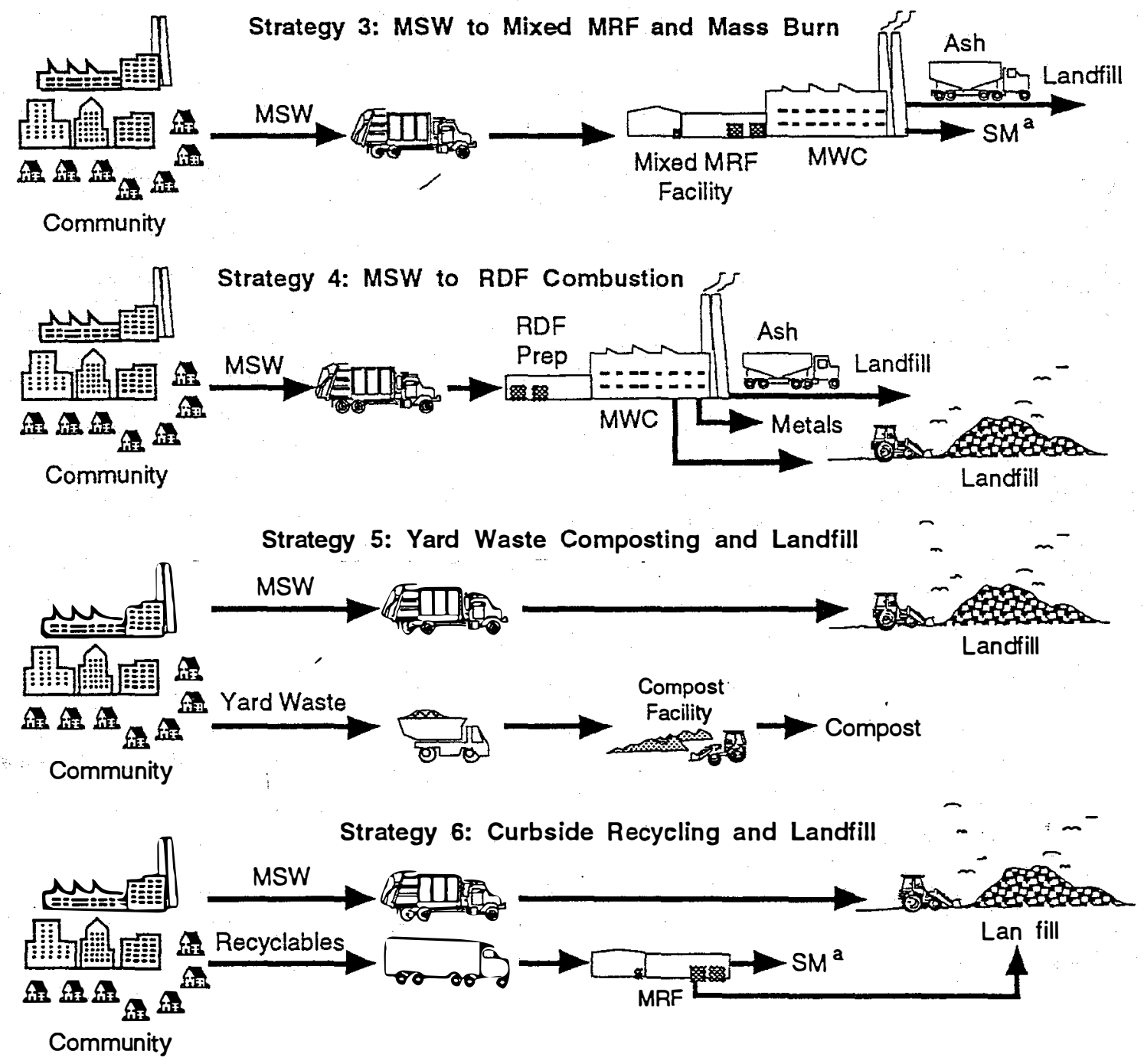

a MRF separated materials for processing by industry. These materials include paper, cardboard, glass, metal, plastic 
Figure ES.1

STRATEGIES BASED ON THE FIVE MAJOR OPTIONS (Concluded)
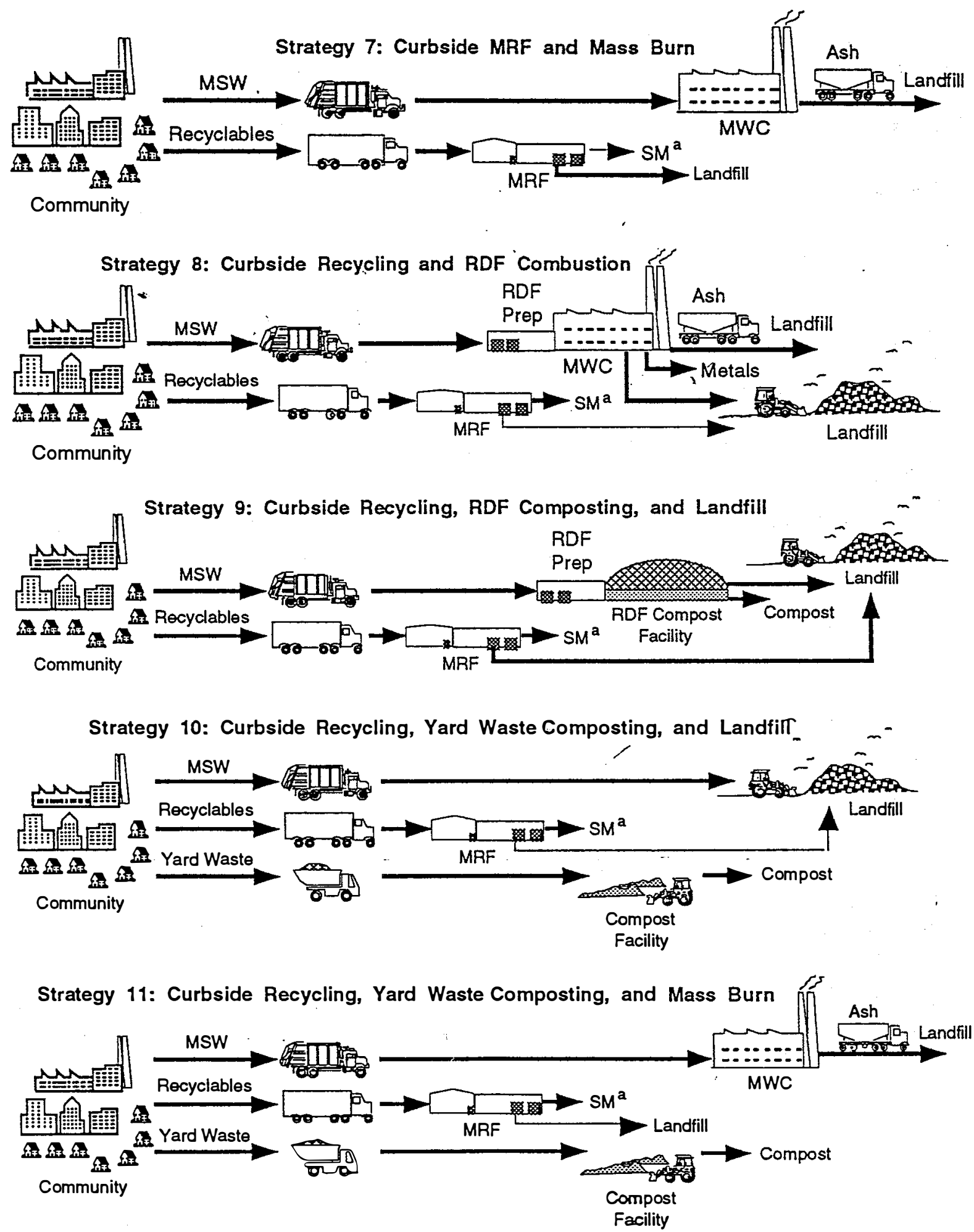

${ }^{a}$ MRF separated materials for processing by industry. These materials include paper, cardboard, glass, metal, plastic 
The results of the energy comparisons for the major strategies are shown in Figure ES.2. The estimates indicate the energy balance for 1 ton of MSW at the curb over the 20-year period. For strategies that include recycling, the energy required for and saved by remanufacturing and reusing the recyclable products is included in the analysis. Energy for transportation of the separated recyclables is a small fraction of the energy required for remanufacture of glass and metal. Transportation energy is quantified in the report, but it is not included in the comparisons shown in Figures ES.2 and ES.3.

To determine the amounts of energy used and saved for remanufactured materials made from the separated recyclables, the products had to be identified. For this analysis, the following assumptions were made:

- Collected aluminum consists mainly of beverage containers used as aluminum sheet can stock. (Other collected aluminum is used to make other aluminum alloys.)

- Collected steel is remanufactured in an electric fumace to sheet steel.

- Glass containers are remanufactured to glass containers of the same or a darker color.

- Paper separated at an MRF is used in a variety of products and exports:

- About $21 \%$ of collected cardboard is exported; almost all of the remaining $79 \%$ is used to make paperboard (which includes cardboard).

- Uses for old newsprint include exports (28\%), remanufactured newsprint (34\%), paperboard (29\%), and tissue (10\%).

- About 50\% of mixed paper is used to make paperboard, $35 \%$ is exported, and $10 \%$ is used for tissue.

Energy savings for remanufacturing aluminum, steel, and glass have been well documented. However, energy data for manufacturing paper products from virgin timber and used paper vary widely. ${ }^{*}$

The combustion strategies produce the greatest energy savings and the largest quantities of exportable electricity. Recovering gas from landfills and buming it to produce heat or electricity is the next most energy-efficient strategy. Recycling achieves smaller energy savings. Composting is the only option thát neither produces nor saves energy.

Figure ES. 3 shows the quantities of electrical energy that could be produced from those strategies that generate a fuel or burn MSW. The illustration compares only the portions of the strategies that involve conversion to heat for electricity generation; energy saved by recycling is excluded (although it is included in the energy balance in Figure ES.2), as is energy used for collection and transportation. The patterns of energy savings in the two figures are quite similar.

* Most or all of the energy used to make about $80 \%$ of virgin paper comes from the wood waste and black liquor. Recycling mills that process only used paper rely on fossil fuels. Published estimates of energy savings from using old paper as a feedstock vary from 10 million Btu per ton of paper product to zero. Some of these estimates vary according to the grade of paper produced. In this report, a value of 5 million Btu per ton, which was reported in at least two studies, was assumed as the energy saving for using cardboard and old newspaper as feedstocks to make new products. 
Figure ES.2

ENERGY ANALYSIS FOR STRATEGIES BASED ON THE FIVE MAJOR OPTIONS (PER TON OF MSW)

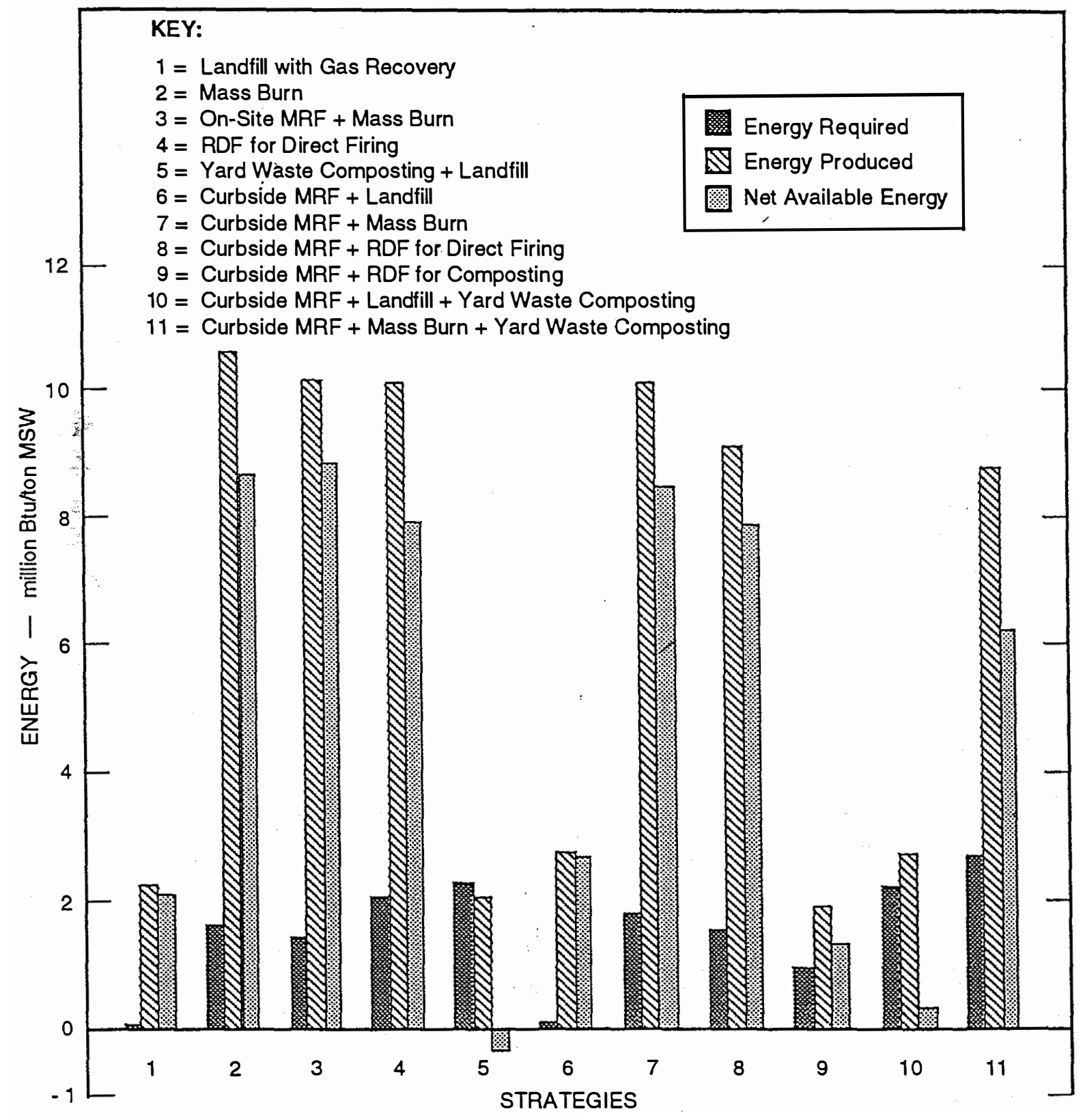


Figure ES.3

\section{NET ELECTRICAL ENERGY (PER TON OF MSW)}

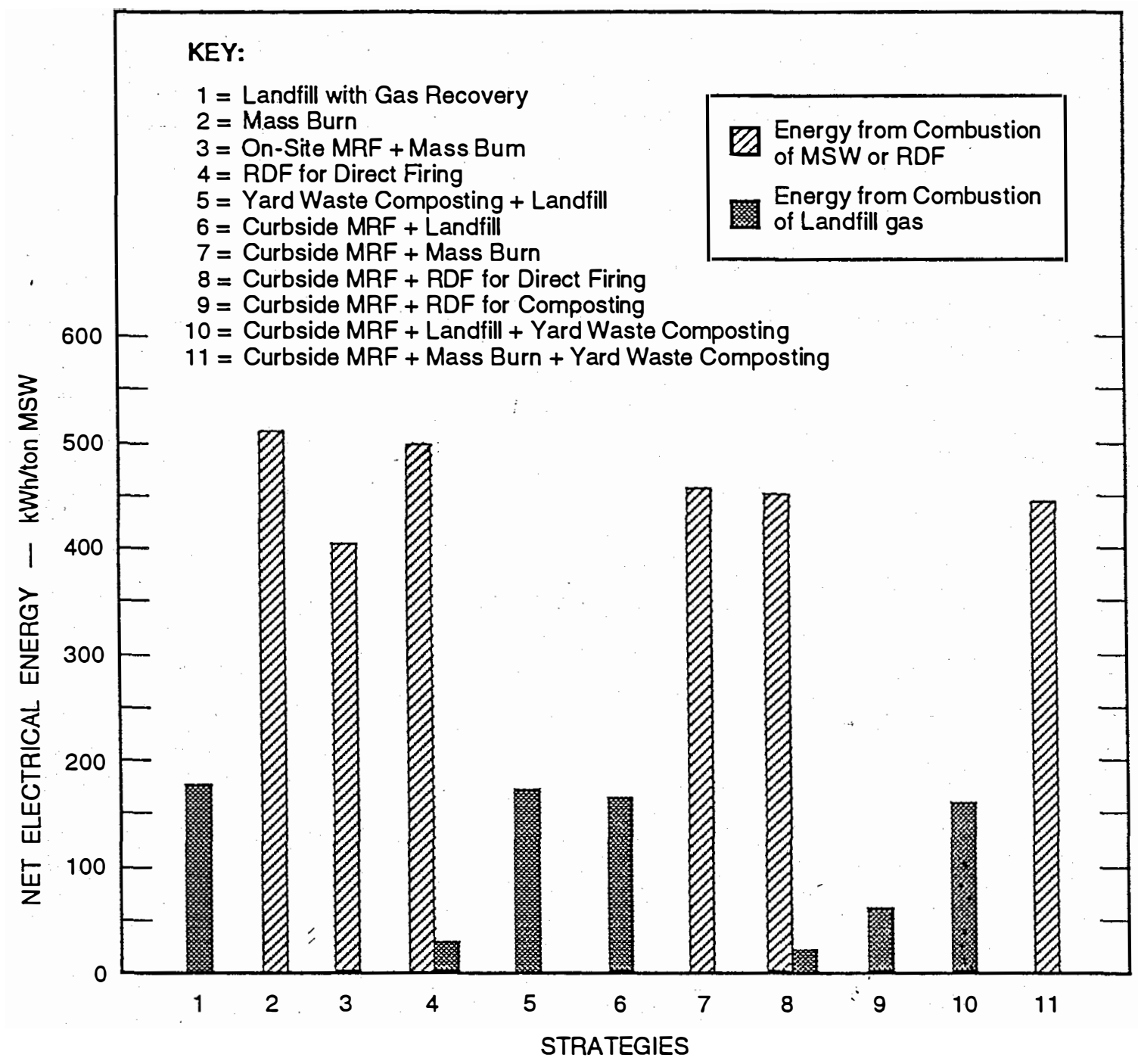




\section{Air Emissions}

Table ES.1 presents air emissions generated by the major integrated waste management strategies (per ton of MSW, over a 20-year period). This table shows releases for each strategy as a whole; Sections 5 through 9 in the report text, Volume I of "Data Summary of Municipal Solid Waste Management Alternatives," break down emissions for key steps.

The releases occur at different rates during the individual steps-collection/transportation, processing, and final disposal-in each strategy. Transportation releases occur while MSW or recyclable materials are in transit; combustion, MRF processing, and recycling also release emissions over a short period of time. Composting and landfilling release air emissions over periods ranging from months to the entire 20 years covered in this life-cycle analysis (landfills actually release emissions for periods much longer than 20 years).

The single values that have been derived for this study are not an adequate basis for making fine distinctions between individual options. Every option has a range of performance values that vary with the design, operation, and maintenance of the equipment used and the nature of the MSW being processed when the environmental releases were measured. For example, extensive data on emissions from mass burning and RDF were used for this analysis, but they cannot be used to determine whether one option will be consistently better than the other in actual operation. Large-scale differences between strategies like landfilling, combustion, or composting, however, can be used to compare the probable results of using one strategy or another.

In general, releases of organic gases to the air are largest for strategies that landfill a large percentage of the MSW. Landfill emissions consist of about $55 \%$ methane; about $2 \%$ by volume is other organic gases, and the remainder is $\mathrm{CO}_{2}$.

In contrast, releases of metals and $\mathrm{CO}_{2}$ to the atmosphere are largest for the strategies that include combustion of a large percentage of the MSW. Combustion emissions include almost no organics, but extremely small quantities of dioxins and furans are emitted (as shown in Table ES.1 in millionths of pounds per ton of MSW). Landfilling and other organic processes (composting, anaerobic digestion) release extremely small quantities of metals, if any, to the air.

Curbside collection of recyclables increases the emissions from the pick up and transportation step of the MSW management strategy, but reduces the emissions from the disp.osal step (landfill or combustion) because the smaller amount of material that remains for disposal produces lower releases. As indicated in Table ES.1, comparisons of Strategies 1 and 6, 2 and 7, and 4 and 8 show that some emissions increase and others decrease, but all the changes are relatively small. This study does not cover releases during the remanufacturing step because inadequate data were found.

\section{Water Emissions}

The water emitted from a landfill is called leachate. Environmental concerns about landfills include the amount of toxic material (metals, organics, dioxins, and other components of MSW) that is released from the landfill by leaching, and the final destination of the leachate. Most new landfills are capped when they are filled, and regulations require them to have a liner and a leachate collection system, and to treat the collected leachate. In spite of these practices, application of a hydrologic model developed by the EPA has shown that about $25 \%$ of the rainwater that falls on a landfill can leak in, and $13 \%$ of the amount that enters the landfill can escape the collection system and leak out through the liner. 


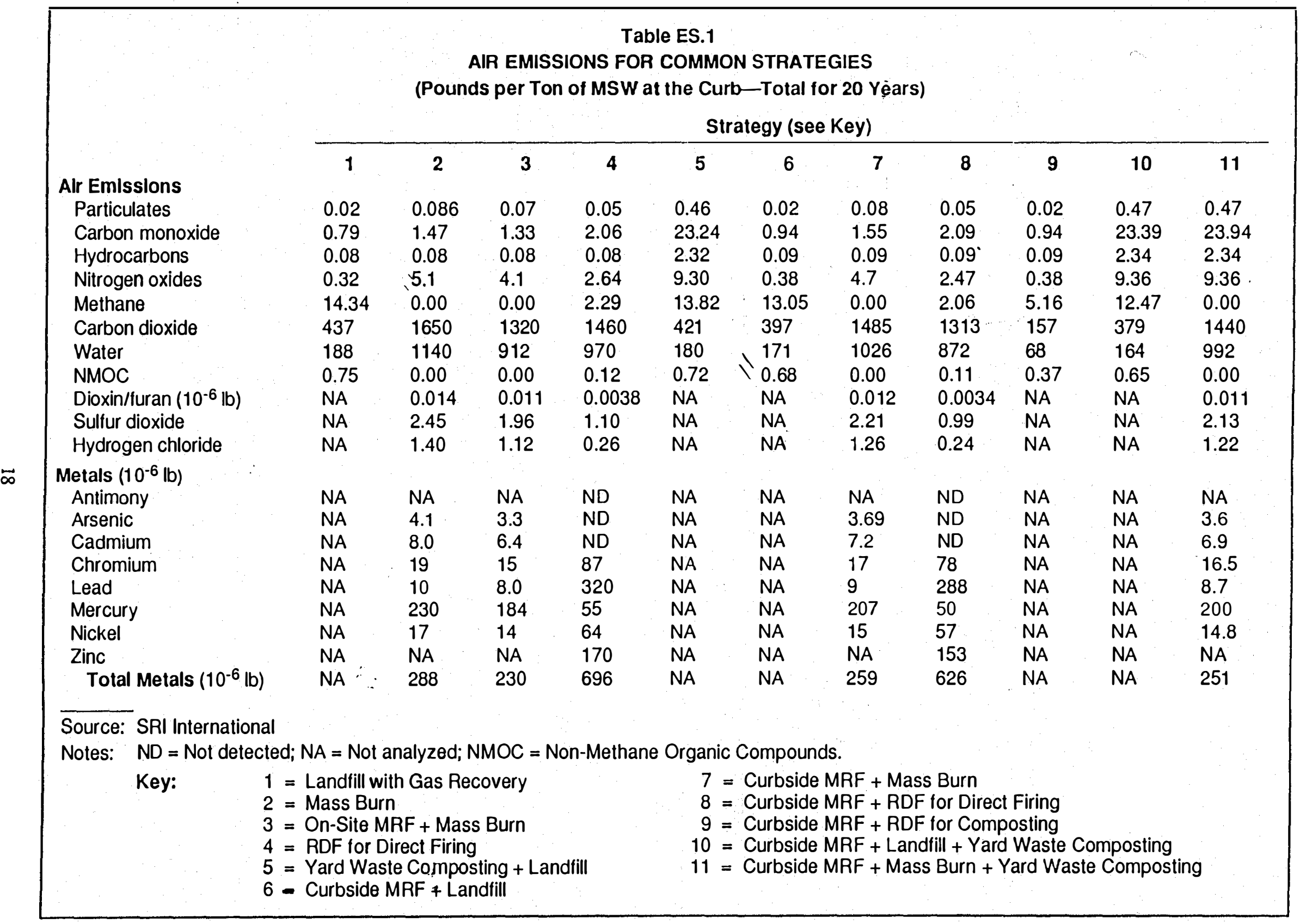


Ash from municipal waste combustors (MWCs) is usually landfilled in separate areas called "ash monofills." Ash monofills can generate 8-10 times less leachate than MSW landfills.

Table ES.2 shows the total quantity and some of the constituents of leachate from landfills and ash monofills for the major integrated waste management strategies (per ton of MSW, over a 20 -year period). The amounts in the table reflect both the percentage that is captured for treatment and the percentage that leaks through the liner. Because leachate is released slowly and continuously over the 20 -year period covered in this report, the concentrations of both organics and metals are quite low.

Organics in leachate from an MSW landfill total about 0.16 pound per ton of MSW over a 20-year period. ${ }^{*}$ Little organic material is left in ash after combustion, and the leachate from an ash monofill includes only about one ten-thousandth of a pound of organics per ton of MSW. ${ }^{\dagger}$

Quantities of metals in the leachate are also lower for ash monofills than for MSW landfills. Most metals dissolve more slowly in ash monofills than they do under the more acid conditions in MSW landfills because the ash and excess scrubber lime are not acidic. For example, the concentration of lead in the MSW leachate is $90 \mu \mathrm{g}$ per liter; lead in leachate from an ash landfill declines to less than $1 \mu \mathrm{g}$ per liter within 2 years. In comparison, a typical drinking water standard for lead permits about $50 \mu \mathrm{g}$ per liter.

This analysis does not cover leaching that might result from the waste from processes that remanufacture paper, metals, and plastics separated from MSW for recycling. Few data on those potentialemissions were found.

\section{Landfill Space}

Figure ES.4 compares landfill volumes required by the common MSW management strategies. The maximum capacity of a landfill is normally determined by volume, not weight. The land area consumed for MSW management is largest if all waste is landfilled; landfill requirements may be up to $90 \%$ lower if recyclables are removed, the remaining MSW is burned, and the ash from combustion is landfilled. Collection and separation of recyclables saves about $14 \%$ of the landfill space in communities that have successful curbside collection programs and market the separated products. A strategy with composting MSW reduces the volume of landfilled material by 50--60\% if the compost can be used (recycled). Even if the compost is landfilled, composting saves about $15-25 \%$ of the landfill space. The amount of landfill space that can be saved by composting separately collected yard waste has not been documented. In the one community used as an example in this study, the savings from composting yard waste totaled less than 5\%. The maximum potential savings would result from curbside collection of all the yard waste in MSW; that could save about $17-20 \%$ by volume of the total landfill space required.

\footnotetext{
* Measured as chemical oxygen demand (COD).

$\dagger$ Measured as total organic carbon (TOC).
} 


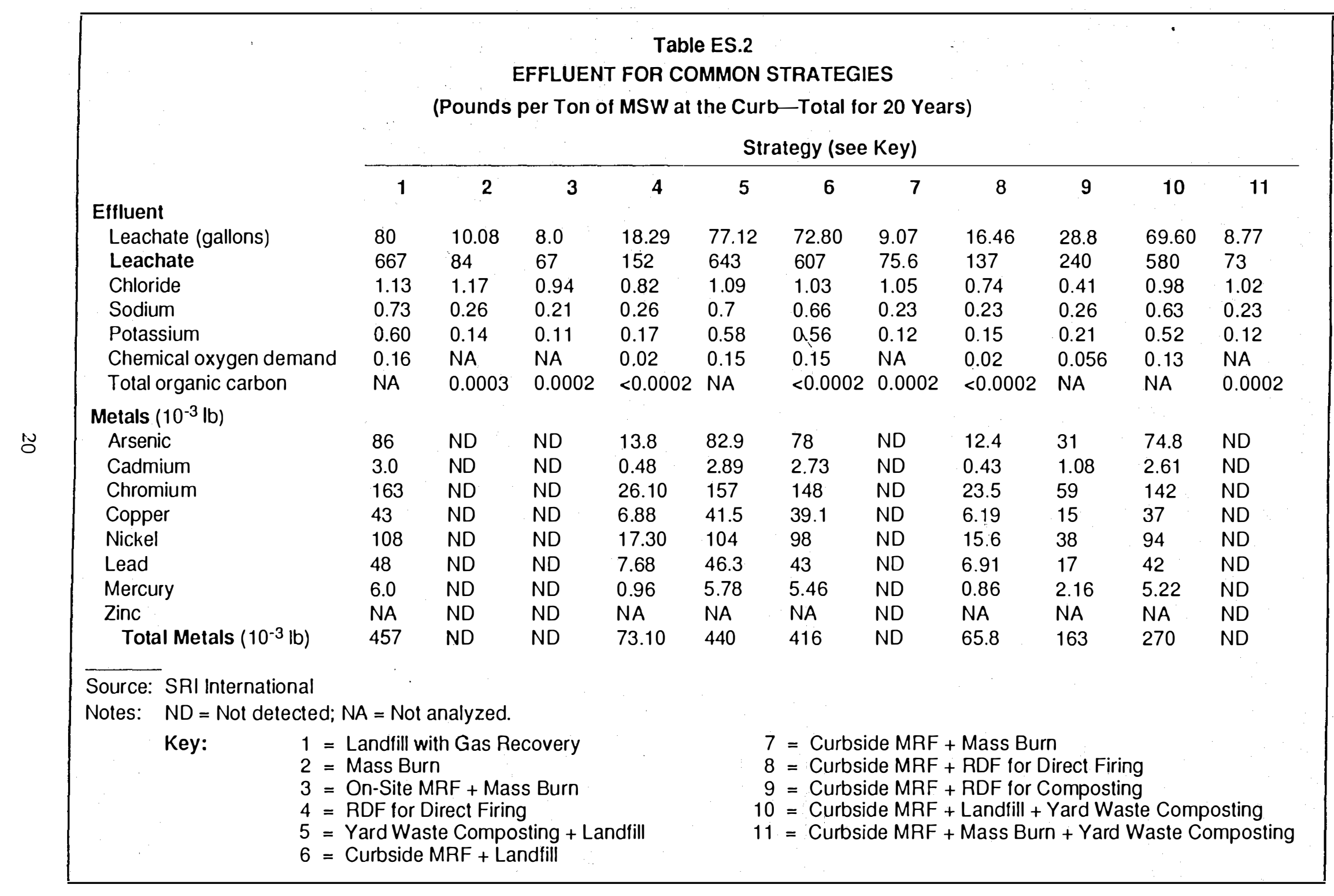




\section{Cost Data for the Major Waste Management Options}

Figures ES.5 through ES.9 show published estimates of the capital costs for the five most common MSW management options. (Costs of operating trucks for curbside collection are not included.) The costs reported in the literature are often incomplete, and published sources often do not fully report on which costs are included and which are excluded. Furthermore, the estimates from different sources are based on a wide variety of assumptions; thus, even estimates for the same technology may not be fully comparable. The inadequacies and inconsistencies in the cost data found in the literature make it imprudent to rely on the estimates in Figures ES.5 through ES. 9 for detailed comparisons of the costs of the various options, for the reasons outlined under "Missing Data." Until cost estimates for waste management options are built from system components using consistent assumptions, the safest way to compare costs is to rely on site-specific quotations from contractors.

\section{MISSING DATA AND RESEARCH NEEDS}

The data gathered for this study vary significantly in quality and consistency. On some topics, no data at all are available. The effects of the limitations on the results of the analysis varied from trivial to major. The 20-year time period chosen for the life-cycle analysis of energy and emissions severely strained the limits of knowledge about many of the options. In addition, the review of the data often indicated the need for research to help to eliminate barriers to the more widespread adoption of certain options. This subsection provides a broad overview of important data gaps and potential research needs.

Cost data in the literature are limited, and the range of capital and operating cost estimates is broad. The capital cost variations reflect inconsistencies in the sources of the estimates rather than predictable variations based on the type of technology or the size of the facility. Some sources fail to report the assumptions on which published cost data are based, and even if the assumptions are known, the bases may be so different that the results are not actually comparable.

For example, the year when a facility was built strongly affects the interest rate paid for the capital, as well as the regulations that apply at the time of construction. Whether a project is privately or publicly funded also affects the interest rates on the capital costs. Location-specific differences, including those in the costs of associated activities such as road improvement, will also affect the comparability of the data. Most of the technologies are typically financed through public bonds in some form, and prospectuses are available for those projects. Even these disclosures may not define or cover all the costs of the facility, however. Some bond issues include costs unrelated to project costs. Operating costs are also affected by local differences in factors such as labor rates, labor contracts, safety rules, and crew sizes that are rarely reported in the open literature. Accounting systems, especially those used by cities and private owners and operators of landfills, vary widely. Cost data on separation/recycling and composting are scarce. To facilitate comparisons of the various strategies for managing MSW, costs for all the systems could be built up from system components using a consistent set of assumptions.

The most extensive data are available on the combustion options. Because combustion is a controlled process that is completed within a short period of time, inputs and outputs, especially of energy, can be measured effectively. 
Figure ES.4

VOLUME LANDFILLED ${ }^{a}$ (PER TON OF MSW)

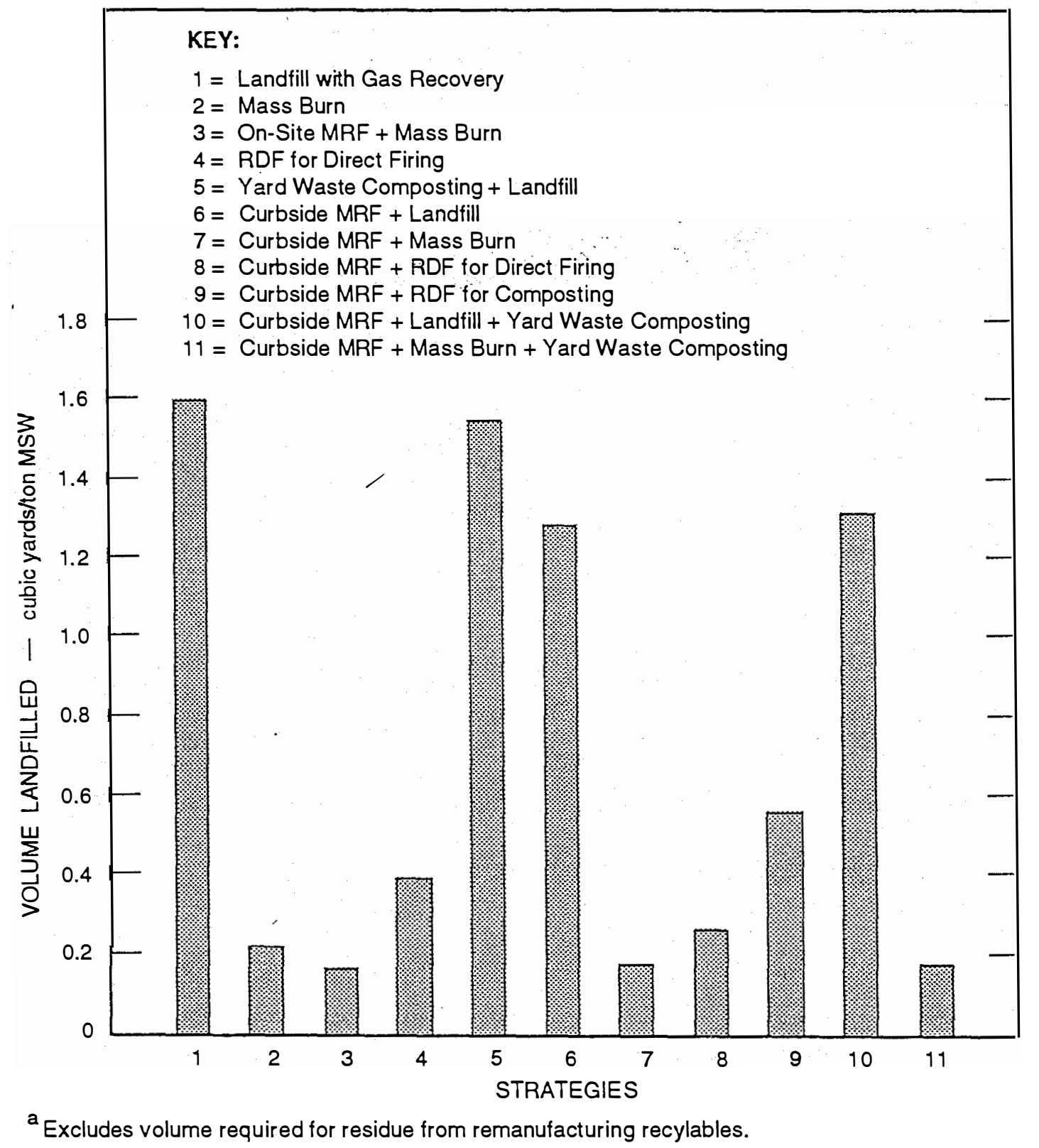


Figure ES.5

FIELD ERECTED MASS BURN - ELECTRICITY PRODUCTION PLANTS EFFECT OF PLANT CAPACITY ON CAPITAL INVESTMENTa

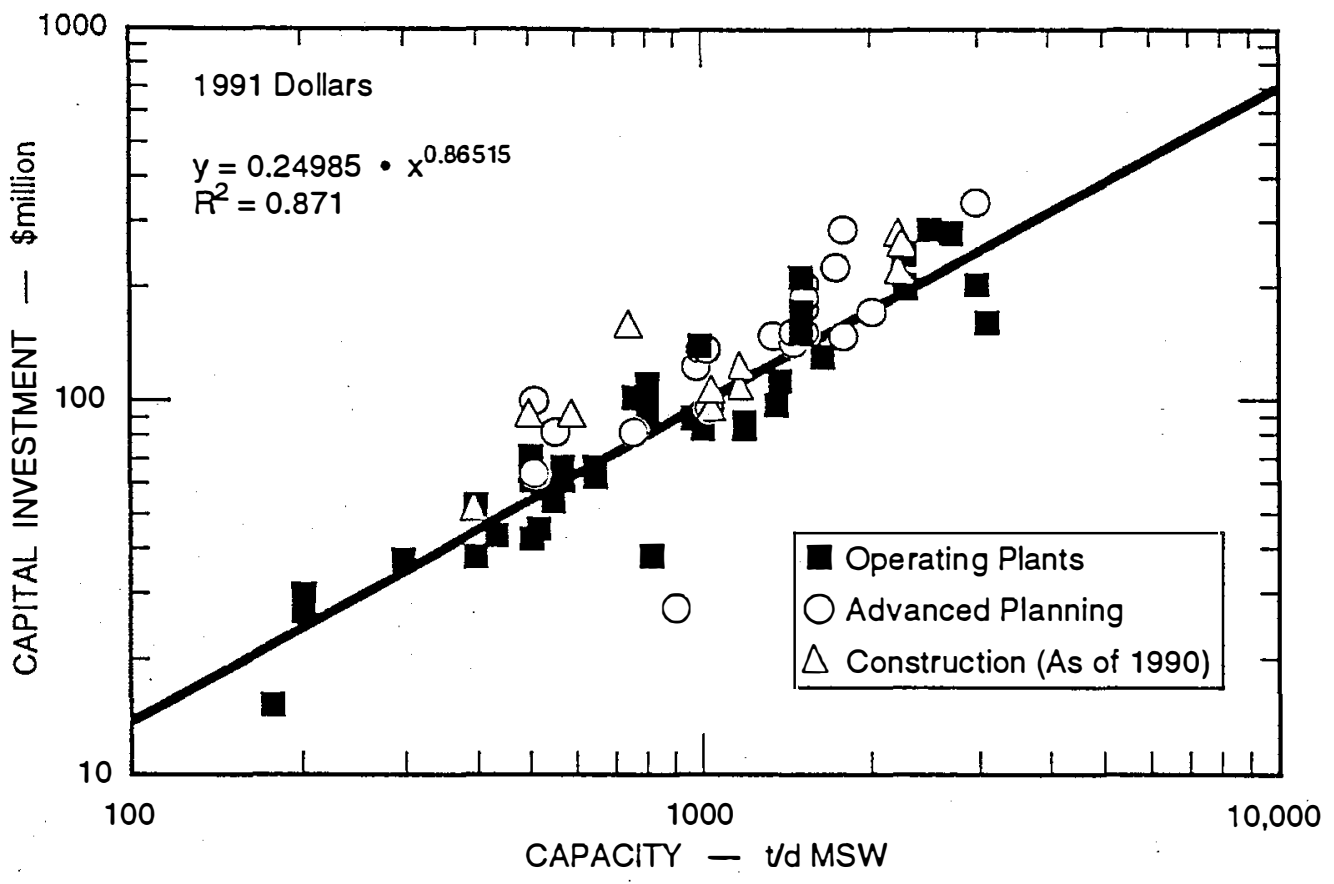

${ }^{a}$ Excluding cost associated with collection (e.g., trucks).

Figure ES.6

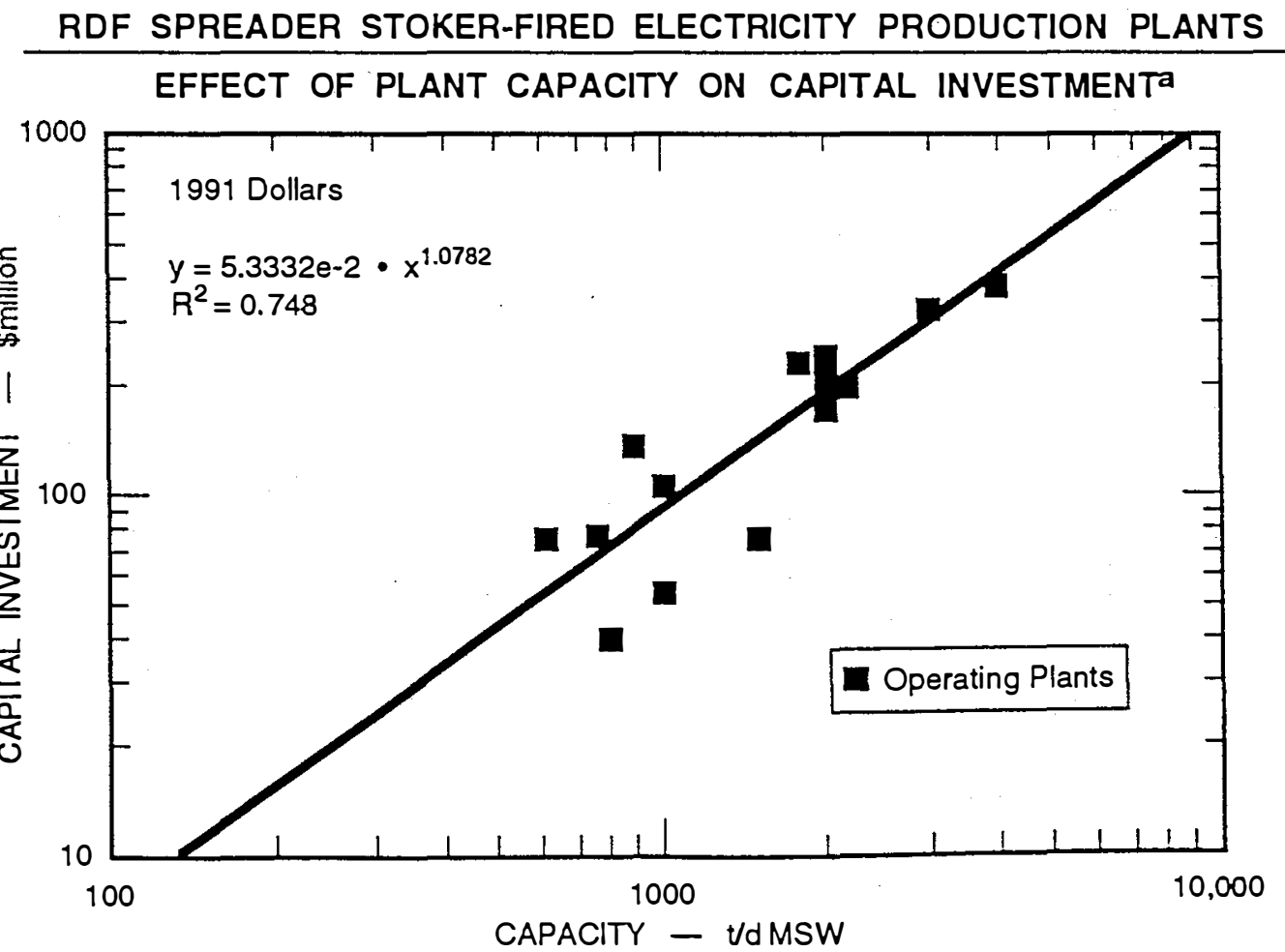

a Excluding cost associated with collection (e.g., trucks). 
Figure ES.7

LANDFILL CAPITAL AND O\&M COSTS

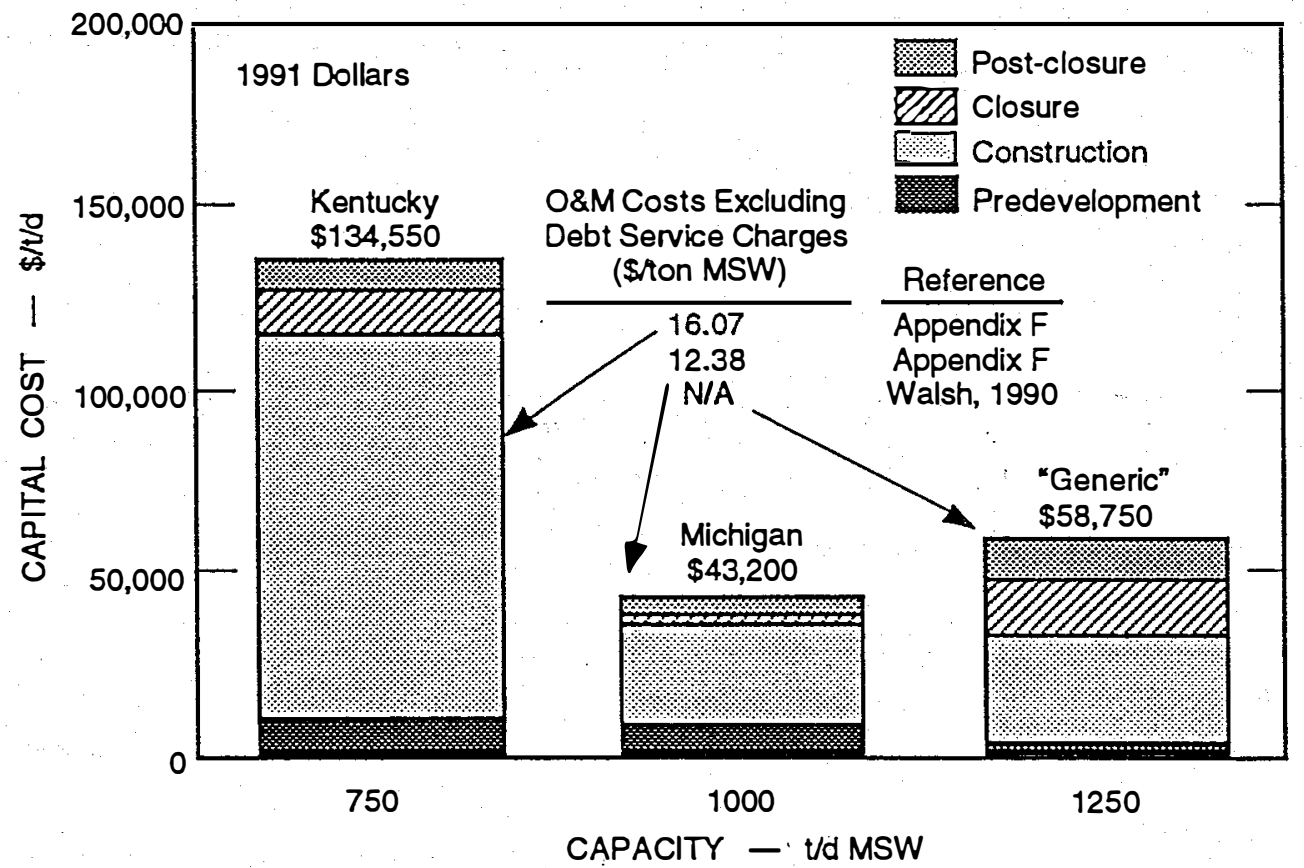

${ }^{a}$ Excluding cost associated with collection (e.g., trucks).

Source: SPI international.

Figure ES.8

MATERIALS RECYCLING FACILITIES (MRF)

EFFECT OF PLANT CAPACITY ON CAPITAL INVESTMENTa ( High Technology)

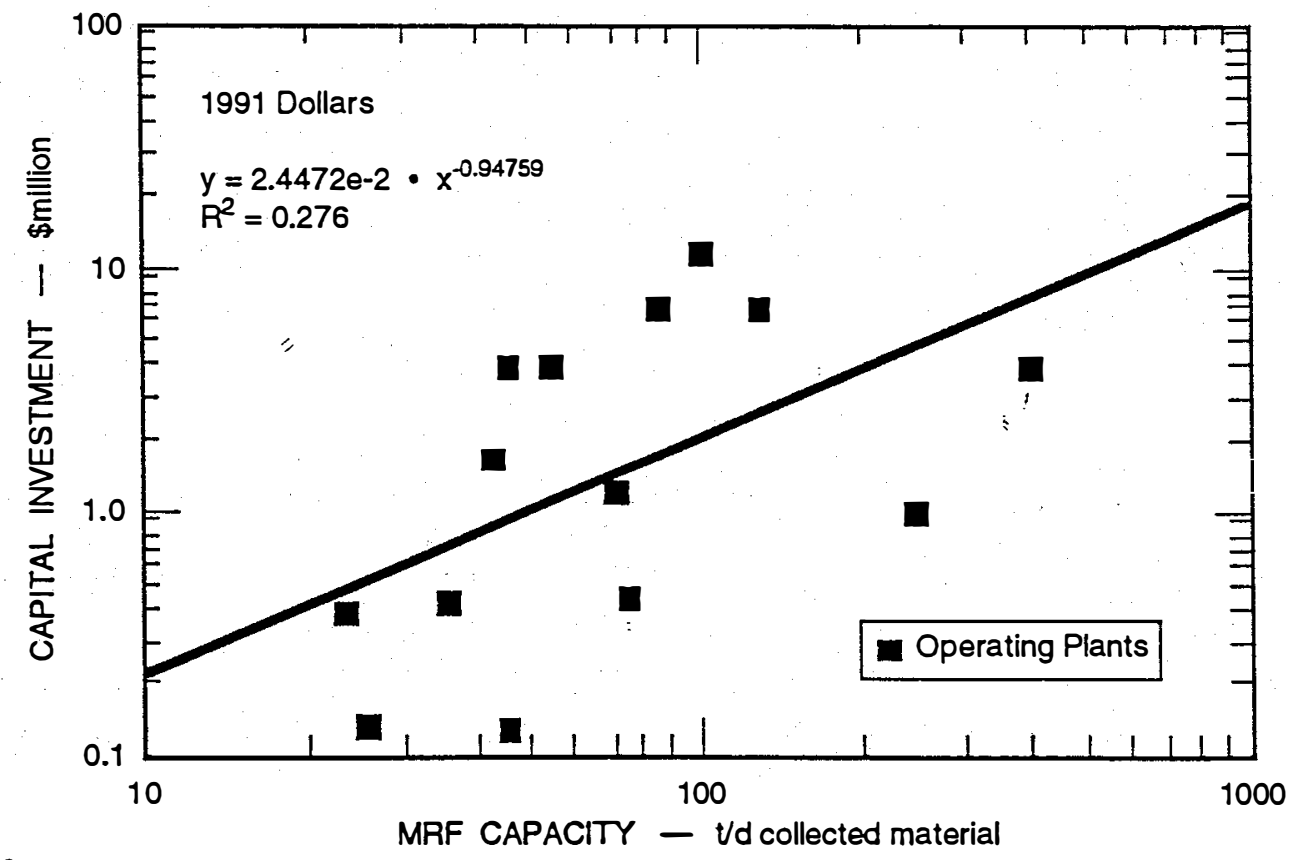

a Excluding cost associated with collection (e.g., trucks). 
Figure ES.9

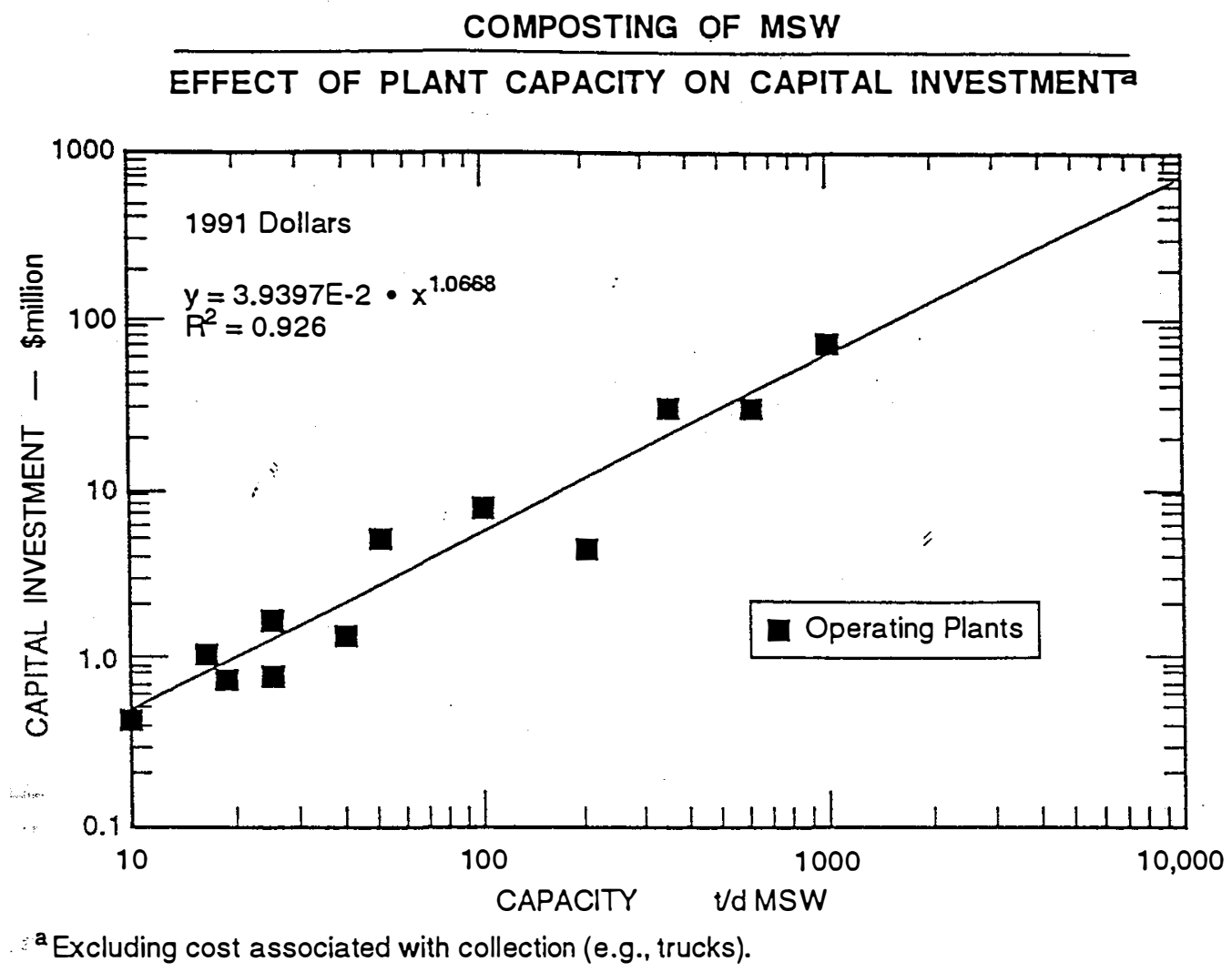

Landfilling is a less controlled process than combustion, and conditions in a landfill change over time. Unexpected leaks and emissions are difficult to locate, and the results of efforts to monitor emissions are therefore less precise for landfills than they are for combustion facilities. The variation from landfill to landfill is also substantial. Sophisticated models of the reactions in a landfill have been constructed, and the data collected in actual studies are generally consistent with the predictions of the models. However, few studies have attempted to quantify air and water releases from landfills over long periiods of time; long-term data on ash monofills are especially scarce.

Data on separation and recycling, with or without curbside collection, are limited, in part because the approach is relatively new. Successful recycling depends more strongly than the other disposal options on nontechnical factors that have not been widely studied. For example, few studies have been found of quantities of recyclables set out for curbside collection over a period of several years. In addition, the success of a recycling operation depends on finding beneficial uses for the products. Extensive data about energy requirements for remanufacturing are available, but only incomplete and out-of-date information on environmental releases during manufacture and remanufacture were found. The lack of systems studies that follow MSW recyclables from curbside to a remanufacturer's product shipping dock is a significant barrier to conducting a life-cycle analysis that compares recycling with alternative MSW management strategies. 
Data on composting of MSW are also limited. Data on emissions during processing are incomplete, and available studies have been less rigorous than analyses of emissions from either landfills or combustors. Data-on emissions from the use of the compost are also scarce, and data on energy requirements are incomplete. Technical and marketing difficulties also constitute barriers to successful application. Composting operations may seem attractive as low-cost alternatives to combustion or landfilling, but inexpensively constructed facilities often suffer serious operating problems. At the other end of the process, at least one large technically successful MSW composting plant has had great difficulty finding markets for the compost product.

Anaerobic digestion is in its infancy in the United States, and no commercial facilities are operating. Adequate data on actual energy use and production, emissions, and composition and use of the compost product cannot be gathered until a commercial plant is constructed and successfully operated.

RDF cofiring is comparatively well characterized. The primary barrier to more widespread use is the difficulty in finding suitable incentives for communities, utilities, and industry to establish mutually beneficial cofiring projects on furnaces with grates.

No commercial gasification or pyrolysis plants are operating in the United States, and the data available on plants operated in the 1970s are out of date. Gasification and pyrolysis of MSW are unproven. At current fossil fuel prices, demand for the gas they produce could be small, and little incentive may existffor additional development of MSW gasification/pyrolysis facilities. If chemical feedstocks can be made by pyrolysis/gasification, the economic considerations may change.

In summary, for combustion processes, extensive data are available on costs, and wellverified data are available on energy and emissions. Less consistent data are available on landfilling, and few data have been found on collection, separation, and remanufacturing and on composting.

\section{OTHER PROJECT DOCUMENTATION}

The findings of this study are published in a two-volume report and 10 appendixes. The appendixes provide detailed summaries of the literature on the various options, as well as bibliographies of the references cited in the appendixes. In addition to this executive summary, those documents include:

"Data Summary of Municipal Solid Waste Management Alternatives. Volume I: Report Text." Final Report, June 1992, SRI International. This report describes major findings in detail.

"Data Summary of Municipal Solid Waste Management Alternatives. Volume II: Exhibits. Final Report, June 1992, SRI International. This volume contains detailed cost summaries, the data base, and other background information.

"Collection and Evaluation of Comparative Data for Waste Management Alternatives. Appendixes": 
Appendix A. Mass Burn Technologies, April 1992, wTe Corporation

Appendix B. RDF Technologies, February 1992, wTe Corporation

Appendix C. Fluidized-Bed Combustion, April 1992, wTe Corporation

Appendix D. Pyrolysis and Gasification of MSW, April 1992, wTe Corporation

Appendix E. Material Recovery/Material Recycling Facilities, April 1992, wTe Corporation

Appendix F. Landfills, April 1992, wTe Corporation

Appendix G. Composting, April 1992, wTe Corporation

Appendix H. Anaerobic Digestion of MSW, April 1992, wTe Corporation

Appendix I: Alphábetically Indexed Bibliography, April 1992, wTe Corporation Appendix J: Numerically Indexed Bibliography, April 1992, wTe Corporation. 


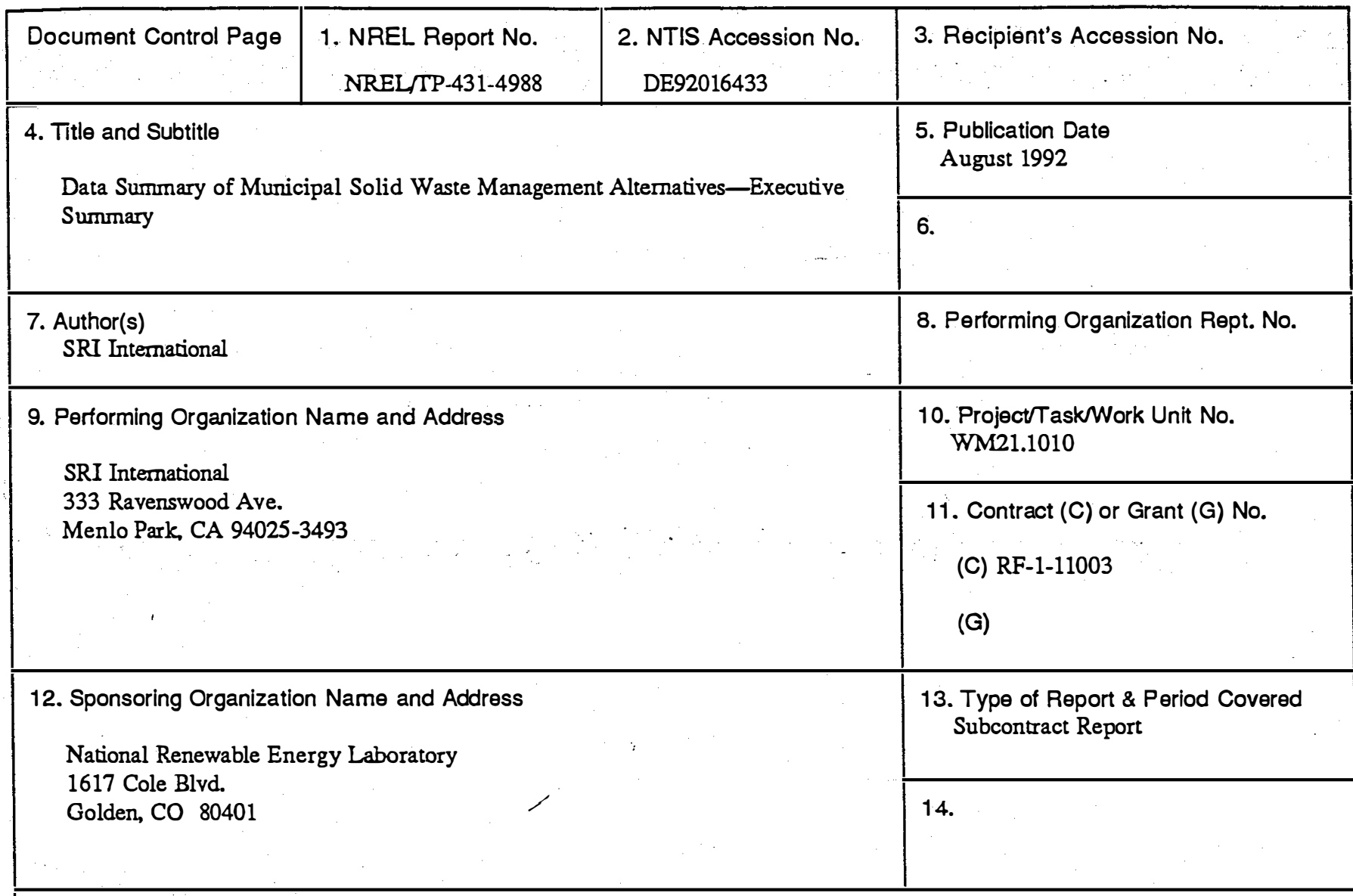

15. Supplementary Notes

NREL Technical Monitor: Bimleshwar Gupta and Philip Shepherd (303) 231-1760

16. Abstract (Limit: 200 words)

The overall objective of the study in this report was to gather data on waste management technologies to allow comparison of various alternatives for managing municipal solid waste (MSW). The specific objectives of the study were to:

1. Compile detailed data for existing waste management technologies on costs, environmental releases, energy requirements and production, and coproducts such as recycled materials and compost.

2. Identify missing information necessary to make energy, economic, and environmental comparisons of various MSW management technologies, and define needed research that could enhance the usefulness of the technology.

3. Develop a data base that can be used to identify the technology that best meets specific criteria defined by a user of the data base.

17. Document Analysis

a. Descriptors

municipal waste; waste to energy; resource recovery; recycling

b. Identifiers/Open-Ended Terms

c. UC Categories

249

18. Availability Statement

National Technical Information Service

U.S. Department of Commerce

5285 Port Royal Road

Springfield, VA 22161
19. No. of Pages

31

20. Price

A03 